UDC 122/129:316.37+323.28

LBC 87.6:66.4(0)

\title{
TERRORISM AS A FROM AND A WAY OF A FORCED CONFLICT RESOLUTION: INTERPRETING THE GENERIC CHARACTERISTICS
}

\author{
Vladimir A. Ponomarev \\ Yurga Institute of Technology (affiliated) National Research Tomsk Polytechnic University, \\ Yurga, Russian Federation
}

\begin{abstract}
The paper deals with the issues related to terrorism as a form of organization and violence against the society. The significant generic features are revealed, which identify the nature of this phenomenon. The biological and social approaches to the phenomenon of terrorism, their interpretation, characteristics and types are described as they stated in works of Russian and foreign scientists. As for the biological approach, the origin of terrorism is interpreted by the statement that violence, wish to use any instruments of violence are in the human nature, a method applied in the general process of natural struggle for existence. The social approach deals mainly with social, social and cultural factors when explaining the phenomenon of terror. The kinds of terrorism can be determined according to the degree and extent of organizational complexity, i.e. personal, group, transnational and state terrorism. Present day terrorism is caused by migration processes and mechanisms evolving in the early $21^{\text {st }}$ century, as well as by separatist sentiments, supported by religious and national feelings. Extremism, inter-ethnic and civilization conflicts, shadow super-national powers becoming stronger due to consolidation of the criminal business, and expansion in the geopolitical sphere, are important factors, which might result in immediate reaction of violently inclined individuals eager to withstand the policy carried out by Western countries, the policy of force. One of the main features of terrorism in the age of globalization is highlighted - its network nature. In network conditions leaders are anonymous and information technologies give members of organizations the opportunity to exclude direct communication. A terrorist network as a system is not regulated and controlled by the state and has a rigid organizational structure. It is concluded that terrorism in total and functional aspect can be described as a violent communication strategy which is unacceptable in the human society. Terrorism appeared because of the world globalization, which has a negative effect on the social development.
\end{abstract}

Key words: terrorism, conflict, violence, globalization, terrorist network, extremism, typology.

УДК 122/129:316.37+323.28

ББК 87.6:66.4(0)

\section{ТЕРРОРИЗМ КАК ФОРМА И СПОСОБ НАСИЛЬСТВЕННОГО РАЗРЕШЕНИЯ КОНФЛИКТА: К ИНТЕРПРЕТАЦИИ РОДОВЫХ ХАРАКТЕРИСТИК}

\section{Владимир Алексеевич Пономарев}

Юргинский технологический институт (филиал) Национального исследовательского Томского политехнического университета, г. Юрга, Российская Федерация

Аннотация. В статье рассматриваются проблемы, связанные с терроризмом как формой организации и выражением насилия по отношению к обществу. Выявляются сущностные родовые характеристики, определяющие природу данного явления. Показаны биологический и социальный подходы к феномену терроризма, его толкование, характеристики и типы в трудах отечественных и зарубежных исследователей. В границах биологического подхода происхождение терроризма интерпретируется тем утверждением, что насилие, 
желание применить средства насилия любого рода лежат в основании природы человека, что является одним из средств в общем процессе естественной борьбы за существование. В проблемном горизонте социального подхода в основном интерпретирована роль социальных, социокультурных факторов в объяснении природы террора. По мере и степени организационной сложности могут быть выделены разновидности терроризма - одиночный, групповой, транснациональный и государственный. Почвой, питающей современный терроризм, являются миграционные процессы и механизмы начала XXI в., а также сепаратистские настроения, усиленные религиозными и национальными чувствами. Экстремизм, проявления межэтнических конфликтов, цивилизационные конфликты, упрочение теневой наднациональной власти, связанной с консолидацией преступного бизнеса, проявление экспансии в геополитической сфере играют роль важных факторов, способных сформировать незамедлительную реакцию тех, кто склонен к террору и противодействию политике стран Запада, «политике силы». Отмечена одна из характерных особенностей терроризма в эпоху глобализации - его сетевой характер. В условиях сети терроризма лидеры анонимны, а информационные технологии создают для членов организации возможность исключить прямую связь. Террористическая сеть как система не регулируется и не контролируется государством и имеет жесткую в организационном плане структуру. Делается вывод о том, что сам терроризм в целостном и функциональном аспекте может быть охарактеризован как насильственная коммуникационная стратегия, неприемлемая в человеческом обществе. Терроризм порожден мировой глобализацией, которая во многом негативно сказывается на развитии общества.

Ключевые слова: терроризм, конфликт, насилие, глобализация, террористическая сеть, экстремизм, типология.

Сегодня на арену активной общественной жизни выходят все новые социальные акторы. Они готовы ради осуществления своих целей к развертыванию широкомасштабной террористической деятельности. Некоторые субъекты, пользуясь отсутствием общепринятой оценки терроризма, применяют его в качестве предлога для реализации своих далеко идущих геополитических планов и проектов глобализации [8, с. 184].

В числе многочисленных проявлений насилия терроризму как форме организации и выражения насилия принадлежит особая роль. Сама проблема терроризма сегодня звучит особенно актуально: в числе глобальных проблем XXI в. ей отведено особое место. Действительно, масштабы этого явления, возникшего достаточно давно, огромны, что позволяет утверждать: человечество находится на грани катастрофы. Изменился сам характер терроризма.

Сегодня можно говорить о том, что жертвы, избираемые террористами, совершающими террористические акты, по сути своей случайны, насилие в террористических актах зачастую носит иррациональный характер, акты террора порой могут восприниматься как лишенные мотивации и непредсказуемые. Перечисленное выше способно породить, и порождает, чувство экзистенциального страха.
В ст. 3 Закона РФ «О противодействии терроризму» [5] сказано о важности определения и ликвидации тех причин, которые ведут к совершению актов террора. Однако отметим, что выявление причин и условий, ведущих к совершению актов террора, вторично. Более важным, на наш взгляд, является выявление сущностных, родовых характеристик, определяющих природу этого явления, как важным является и определение границы между терроризмом и иными феноменами, в основе которых проявляет себя такой фактор, как насилие. Круг этих явлений достаточно широк - экстремизм, геноцид, война. Упоминание термина «терроризм» предполагает такую особенность этого феномена, как умышленное и систематическое использование в достижении целей насильственных средств.

Отмечая роль насилия как фактора, характерного для террористических действий, аналитики Института по изучению международного терроризма во главе с директором Дж. Александером видят его специфику в том, что террористические акты зачастую являются формой и способом разрешения того конфликта, участниками которого являются маргиналы, проявляющие свое недовольство [1, с. 6].

На насилии как факторе сосредотачивает внимание П. Уилкинсон, отождествляя террор с отдельными актами диверсии, атаками 
на собственность, борьбой политических организаций и междоусобной борьбой, политическим терроризмом, локальными мелкомасштабными партизанскими операциями, партизанскими рейдами за пределами страны. В то же время он отмечает, что в нанесении вреда гражданскому населению заключается главное различие между партизанами и террористами. Партизаны, используя часто недостаточное оружие, воюют в основном малочисленными отрядами, зачастую с соблюдением правил традиционной войны. Они берут и обменивают пленных, уважают права невоюющего населения. Террористы, не разграничивая используемые ими средства, совершают массовые убийства и распространяют на гражданское население «всеобщий террор» [27, p. 54].

В предложенном автором варианте классификации типов насилия акцент сделан на определенной похожести этих типов; однако именно эта классификация не позволяет выявить специфику черт терроризма и охарактеризовать такие составляющие насилия, как идеологические и организационные. Приведем классификацию типов насилия, где уделяется внимание преторианскому, внутриобщинному, протестующему, репрессивному, оппозиционному, террористическому, революционному и контрреволюционному типам, а также такому типу насилия, как военный [26].

На наш взгляд, П. Уилкинсоном не учтено то обстоятельство, что не всякое насилие является терроризмом, но насилием является всякий терроризм; особенность же терроризма как формы насилия проявляется в том, что в любом террористическом акте нормы права, равно как и нравственные императивы, оказываются полностью и намеренно проигнорированными, попранными.

В целом можно говорить о различии таких подходов к явлению терроризма, как подход биологический и социальный. В границах биологического подхода происхождение терроризма интерпретируется тем утверждением, что насилие, желание применить средства насилия любого рода лежит в основании природы человека; это одно из средств в общем процессе естественной борьбы за существование. Насилие в пространстве свободных и сознательных действий человека, в соответ- ствии с биологическим подходом, будет иметь место всегда (осуществление физического принуждения, убийство или угроза убийства, навязывание своей воли). Желание «заставить других людей жить по своей воле» [18, c. 168] - неуничтожимое желание, всегда свойственное природе человека. И хотя возможны попытки оправдания насилия на основании моральных аргументов [4], биологическая концепция происхождения терроризма в ряду других подходов имеет право на существование.

Другим подходом является социальный. В проблемном горизонте обозначенного подхода в основном интерпретирована роль социальных, социокультурных факторов в объяснении природы террора. Именно в границах социального подхода сформированы «концепция красной сети» и «концепция общества вседозволенности». Эти концепции в числе доминирующих детерминант террористических действий акцентируют внимание на роли внешнего покровительства террора, на роли демократических режимов в осуществлении террористических актов.

О роли и значении демократических механизмов и ценностей как питательной среды террора пишет, к примеру, в «Заметках о терроризме» [15] В.Е. Петрищев: демократические гарантии и ценности - свобода слова, печати, собраний, свобода и неприкосновенность приватной жизни; осуществляющие террористические акты, используя эти свободы, вызывают у правительств желание ограничить сферу подобной свободы, когда речь идет об актах террора. Отметим, что В.Е. Петрищев, как и У. Лакер, считает невозможным дать само определение терроризма в силу того, что подходы к этому феномену характеризуются отношением дополнительности. Феномен терроризма многоаспектен и сложен. Он может быть рассмотрен с позиции сути его деструктивных функций, в дискурсе политологического подхода, в социально-психологическом и историко-культурном ключе, наконец, с позиции правовой квалификации, ведь терроризм это и вид преступной деятельности.

Проявлением установок социального подхода к феномену терроризма является позиция У. Лакера. Задаваясь вопросом о том, почему в странах с тоталитарными, комму- 
нистическими режимами невозможен террор, У. Лакер объясняет это обстоятельство полным отсутствием свободы или ее минимумом [10].

На наш взгляд, терроризм как форма насилия может быть охарактеризован в широком спектре следующих свойств. Террористические акты и действия, осуществляемые в различных целях (это могут быть идеологические, финансовые, психологические цели) посредством применения силы, с угрозой применения силы, направлены на невинных. Направленность террористических актов на невиновных С.Л. Удовик называет «квинтэссенцией террора», его истинной основой (лат. quintsessentis - истинная, основа существующего) [19].

Объявляя свои цели в полной мере законными, террористы эти цели определяют исходя из их символической сути, используя при этом понятие «ненавидимое». Террористические действия по сути своей ориентированы на полное игнорирование закона и морали, уголовно-правовой сути совершаемого, на полное отрицание самой возможности использования преимуществ правовых и социальных способов решения конфликтообразующих проблем. Террористический акт всегда использует публичность; он публичен ради того, чтобы «принудительная стратегия» получила в этом акте свою эффективную реализацию: акт террора по сути своей всегда является актом устрашения. Террористический акт всегда нуждается в огласке; вне публичной манеры его совершения этот акт невозможен, как невозможно характеризовать действие как террористическое вне открытой формы предъявляемых требований. Сам терроризм, если его рассматривать целостно и функционально, может быть охарактеризован как насильственная коммуникационная стратегия.

Характерную особенность терроризма как стратегии, на наш взгляд, отмечает В.В. Устинов, анализируя стандарты и методы международного опыта борьбы с терроризмом. Автор отмечает, что «...терроризм это стратегия посредством использования насилия произвести определенный эффект на группу населения. При обращении к государственной классификации терроризм - это стратегия одного из четырех “идеальных типов” стратегий, посредством которых группа, находящаяся не у власти, может вызвать насильственные социальные изменения. Другие три - это государственный переворот, восстание и партизанская война» [20, с. 14].

Перефразируя Карла фон Клаузевица, определяющего войну не только как акт политики, но и как подлинное орудие политики, как продолжение отношений посредством использования иных средств, будем ориентироваться на интерпретацию терроризма как орудия и тактики политики. Масштабность терроризма, выраженная в количестве невинных жертв и связи с политикой, позволяет относить его к особой разновидности войн. Подобная интерпретация обусловлена многофункциональными особенностями терроризма, его специфичностью: акты террора могут быть осуществимы в любых социокультурных средах и условиях и применимы для реализации различных целей, в числе которых религиозные, экономические, политические.

Одной из характерных особенностей терроризма в эпоху глобализации является его сетевой характер - «эта размытость образа врага в общественном сознании, способность приписывать угрозе любое лицо позволяет оправдывать превентивные меры против каждого» $[11$, с. 8$]$. В условиях сети терроризма лидеры анонимны, а информационные технологии создают возможность для членов организации исключить прямую связь. По своей сути, считает Е.Н. Малышева, терроризм форма войны, действия сторон в ней асимметричны; за счет этой асимметрии даже уступающий в технологическом и организационном отношении противник может осуществлять долгосрочную стратегию [11, с. 9].

Сетевые структуры терроризма являются (по мнению Д.Г. Горина [3], М. Кастельса [7; 24], М. Сейджмана [16]) средством глобализации, одновременно это и воплощение глобализации; террористическая сеть имеет общепланетарный характер, базисом для рекрутирования в этой сети является террористическая идеология. Террористическая сеть как система не регулируется и не контролируется государством и имеет жесткую в организационном плане структуру.

В отечественной литературе помимо понятия «новый терроризм» (это понятие 
введено В.Г. Федотовой в монографическом исследовании «Хорошее общество» [22] и обозначает терроризм, порожденный ситуацией глобализации) используется понятие «супертерроризм», введенное А.В. Федоровым [17, с. 8-9].

Авторы монографического исследования из серии «Национальная и глобальная безопасность» - «Супертерроризм: новый вызов нового века», говоря о супертерроризме, отмечают системность, наступательность, массовость, непредсказуемость этой разновидности терроризма; при этом конечной целью является формирование чувства панического, непередаваемого, непреодолимого страха, равно как и чувства абсолютного отсутствия безопасности [17].

В этом плане и смысле можно говорить о превентивном устрашении, равно как и о самом терроризме как о возможности и способе управления массами через ориентацию на порождаемые через устрашение, ужас и страх. Террорист смотрит на жертвы совершаемого акта как на нечто промежуточное; наряду с этой целью существенной является и цель более далекая и одновременно отличающаяся конкретностью, поскольку любой акт террора - это коллективный акт, он направлен на социум в целом, на то, чтобы обеспечить паническую деморализацию. Особенностью террористического акта является и то, что в нем насилие применено в отношении одного круга лиц, но масштаб психологического воздействия оказывается значительно шире: более широкий круг свидетелей террористического действия может быть склонен к определенным типу и формам поведения. Хотя террористы декларируют тактические цели, подтекстом идут и цели стратегического уровня. Именно стратегия террора способна определить как тактику и средства террора, так и его цели.

Что же, однако, является предпосылкой деятельности террориста? Как форма и способ разрешения конфликта посредством акта насилия, террористическое действие имеет совокупность причин. Когда-то Р. Мертон назвал совершающего акт террора «социальным критиком общества», полагая, что, совершая подобное действие, субъект тем самым демонстрирует, что общество далеко от идеала [12].
Как социальную технологию, посредством которой осуществляется коррекция (в нужном для террористов отношении и направлении) принятой властью стратегии управления, интерпретирует терроризм Т.Ф. Фазылова [21, с. 13].

В.В. Устинов [20], М.В. Назаркин [13], В. и С. Маллисон [25] в своих трудах в качестве первопричин называют социальные конфликты, несправедливость, лишенность прав, что можно объединить как социально-политические, историко-культурные, экономические причины и предпосылки актов террора.

В Законе РФ «О противодействии терроризму» говорится о понимаемых как первопричины терроризма глубоком экономическом кризисе; хронической политической нестабильности; общем структурном кризисе государства и его институтов; разрушении исторических, культурных, нравственных, гуманистических ценностей; росте национализма, национальной нетерпимости, религиозного экстремизма и сепаратистских настроений; слабости государственного аппарата; низком профессионализме спецслужб; падении авторитета власти, закона, веры в ее способность обеспечить безопасность; о значительном нелегальном рынке оружия и легкости его приобретения; о проблемах в международном подходе к вопросам терроризма, проявлении интересов других государств, зарубежных террористических, религиозных, национал-радикальных организаций; о сдвигах в социальной структуре, приведших к маргинализации социальных групп; наконец, о падении жизненного уровня, о состоянии психологического дискомфорта, тревоги и безысходности, об обостренном чувстве социальной неустроенности, незащищенности значительной части населения; о росте социальной агрессивности [5].

Среди причин террористических актов в законе отмечена борьба за власть политических партий либо общественных объединений, преследующих политические цели, либо лидеров отдельных групп. Важную предпосылку террористической деятельности следует связывать с волевой установкой на получение или увеличение власти (влияния), с устранением причин, мешающих реализации личных политических амбиций лиц, что обусловливает 
выбор террористических методов действий. Это обстоятельство подчеркнуто в Концепции национальной безопасности РФ, утвержденной Указом Президента РФ; в этом документе рост масштабов террористических актов увязан с такими фактами, как масштабы передела собственности, рост властных амбиций лидеров, представляющих как групповые, так и национальные интересы.

В проведенном исследовании мы будем ориентироваться на следующее толкование современного терроризма, предложенное Е.П. Кожушко [9]. Автор исходит из понимания терроризма как специфическим образом организованного насилия, как вида социального взаимодействия. Он считает, что цели терроризма, используемая им система средств, способы осуществления актов террора, наконец, результаты влияния позволяют относить терроризм к разновидности войн. Осуществляют же эти направленные против общества действия в высшей мере агрессивные, организованные, подготовленные в определенной идеологической системе исполнители. При этом совокупность экстремистских идей и актов, их реализация требуют специфических организационных форм и отношений.

Считаем, что дополнением к приведенной точке зрения Е.П. Кожушко может быть позиция А.В. Яшлавского: автор, понимая под терроризмом незаконное использование насилия, равно как и угрозы насилия на негосударственном уровне (целью чего выступает запугивание, трансформация правительственной стратегии), считает, что конечной целью подобных действий являются цели политические либо социальные. Однако автор справедливо полагает необходимым давать в определении терроризма и информационную составляющую [23, с. 26].

Особое внимание следует обратить на психологическую составляющую системы предпосылок террористических актов. Хотя социально-экономические факторы - включая бедность, безработицу и низкий уровень образования - могут помочь в объяснении аспектов поддержки терроризма в Северной Ирландии и Нидерландах, но они не работают в случае с терроризмом в Западной Германии, где типичным представителем террориста является неженатый мужчина 22-24 лет, имеющий хотя бы частичное университетское образование, часто гуманитарное, отпрыск семей среднего и высшего класса, чьи террористические наклонности в международном подходе к вопросам терроризма стали итогом разочарования, смешанного с анархическими и нигилистскими взглядами [20, с. 23-24].

Зачастую механизм действий террориста запускается наличием состояния безысходности, психологическим дискомфортом, что заставляет человека характеризовать положение, в котором он существует, как драматическое. Речь может идти о национальной общности, об объединившихся на основе политических либо религиозных убеждений, когда в результате ущемления интересов формируется вывод о языке насилия как единственно возможном, что современный терроризм в качестве своей предпосылки имеет факторы как объективного, так и субъективного характера.

В числе субъективных факторов могут быть названы психологические особенности совершающих акты террора - это склонность к агрессии, насилию, жестокости; это могут быть люди-«зомби», то есть люди, мораль которых деформирована, как деформирована и ценностная система. Как правило, это фанатики. Они были всегда, и это обстоятельство не позволяет нам принять тезис Т.Ф. Фазыловой - «терроризм социально детерминирован. Если бы в мире царила политическая и социальная справедливость, отсутствовала бы почва для возникновения терроризма» [21, с. 9]. В числе объективных факторов, способствующих проявлениям терроризма, могут быть названы те, что связаны, в частности, и с процессами и ценностями глобализации, не принимаемыми и не одобряемыми (в силу причин нравственного и правового характера) значительной частью населения мира.

Анализирующая эту проблему Е.Н. Малышева называет глобализацию важнейшей причиной активизации терроризма. Именно глобализация меняет онтологический статус терроризма, и причина этого - планетарная интеграция, обнаруживающая весь сложный комплекс противоречий, трансформация двухполюсного миропорядка, и как итог - цивилизационный кризис. С глобализацией как пла- 
нетарной интеграцией связано и появление международного терроризма. Автор пишет, что «резкая дифференциация государств в процессе глобализации стимулирует развитие международного терроризма как одной из форм асимметричного ответа на силовое давление. В процессе глобализации на мировой арене появляются новые самостоятельные элементы - транснациональные структуры, имеющие собственные корпоративные интересы. Эти интересы далеко не всегда могут совпадать с интересами государств. По мере увеличения транснациональных организаций роль государства снижается - сокращаются возможности контроля за внутриполитической ситуацией, теряется суверенитет над национальной экономикой; многие функции государства переходят к транснациональным корпорациям. Учитывая, что основной способ силовых действий сепаратистов опирается на партизанские методы борьбы, террористические акции, то транснациональные криминальные структуры, местные сепаратистские группировки и международные террористические организации тесно между собой связаны» $[11$, c. 12$]$.

Движение антиглобалистов и международный терроризм могут быть проанализированы как объединение радикальных политических сил. Среди детерминирующих терроризм факторов - западноцентристская модель мира, ориентированная на ценности общества потребления. Эта модель играет роль фактоpa, ведущего к напряжению и расколу в мире, что проявляется в экстремизме, межэтнических, цивилизационных конфликтах, в упрочении теневой наднациональной власти, связанной с консолидацией преступного бизнеса. Проявление экспансии в геополитической сфере также играет роль важного фактора, способного сформировать незамедлительную реакцию тех, кто склонен к террору, к насильственным формам противодействия этому, как и противодействия политике стран Запада, «политике силы».

В работе «Что такое глобализация?» в числе объективных факторов, влияющих на проявление террористических устремлений, У. Бек называет возникновение транснациональных государств, корпоративные интересы которых представляют собой нечто еди- ное с интересами криминального мира, транснациональных структур [2, с. 47].

Наконец, почвой, питающей современный терроризм, являются также миграционные процессы и механизмы, обнаружившие себя в начале XXI века. Мигранты пополняют ряды тех, кто готов совершать террористические акты и действия, в силу своей социальной незащищенности, полного отсутствия перспектив. Терроризм питают и сепаратистские настроения, усиленные религиозными и национальными чувствами. Являясь проявлением рассогласованности системы управления и тех, кем управляют, терроризм практически всегда имеет политический подтекст; он является проявлением энтропийных процессов в обществе, сопряжен с неустойчивостью и хаосом.

Что касается типологизации терроризма, то ее основаниями могут явиться: сфера действия (внутригосударственный - транснациональный), социально-политическая ориентация (левый - правый), способы воздействия на объект (демонстративный - инструментальный), средства осуществления террора, цель террористического акта, идентичность субъектов террора (религиозный, национально-сепаратистский). По мере и степени организационной сложности могут быть выделены такие разновидности терроризма, как одиночный, групповой, транснациональный и государственный.

Типология терроризма сегодня не являет собой окончательный вариант. Анализирующие теорию и практику терроризма пишут сегодня о достаточно современных формах этого явления.

Рассуждая о «супертерроризме» как вызове XXI в., М.В. Назаркин считает возможным выделить психологический, технологический и информационный его типы [13]. Последний подтип, так называемый информационный, в частности, может проявить себя посредством уничтожения информационных систем через компьютерную сеть. Есть и иной смысл понятия информационного терроризма. Это тот духовный терроризм, который в последнее десятилетие принял массовый, тотальный характер; жертвами его стали миллионы граждан России - в переносном и статистическом смысле. Информация, поставляемая 
четвертой властью, сообщает о ставших трагическими нормами событиях нашей жизни: уничтожении института семьи, наркомании, катастрофическом падении рождаемости, нездоровом образе жизни.

В основе многого из перечисленного безнаказанная пропаганда недопустимого. Сегодня демографическая ситуация в России уже давно признается неблагополучной, более того, Росстат, оценивая результаты переписи населения 2002 г., назвал положение дел в этой области удручающим. В результате продолжающейся не просто депопуляции, а настоящего демографического кризиса численность населения собственно России ежегодно сокращается на сотни тысяч человек [14, с. 44].

Одновременно молодежными СМИ без устали пропагандируется «безопасный» («бездетный») секс. Концептуальные ТВ-лозунги, телевизионный экран превращены в действующие пособия по взращиванию совершающих террористические акты. Информационный терроризм ненаказуем. Террористов-ваххабитов ищут, находят, судят. Информационных террористов (зачастую это «лидеры мнения» известные рок- и поп-музыканты и певцы, артисты и писатели) знают и видят все, но они неподсудны, и свобода слова оборачивается свободой убивать.

Таким образом, терроризм как форма и способ насильственного разрешения конфликта является неприемлемым в человеческом обществе. Он - деструктивное явление современности. Терроризм низвергает человечество на грань катастрофы. В основе его природы заложен фактор насилия. Терроризм порожден мировой глобализацией, которая во многом негативно сказывается на развитии общества. Для решения его проблем нужны другие, ненасильственные подходы к их преодолению. Этого можно достичь путем выявления сущностных родовых характеристик, определяющих природу терроризма. В итоге борьба с этим явлением будет более эффективной.

На сегодняшний день индивидам важно научиться правильно выстраивать диалогичные отношения для того, чтобы выявлять и использовать эффективные и оправданные методы снижения напряженности в социуме, способствующие повышению его толерантности и стабильности в условиях плюрализма интересов, ценностей, традиций и т. п. [6, с. 119]

\section{СПИСОК ЛИТЕРАТУРЫ}

1. Батюшкин, С. Вакцина от «чумы» / С. Батюшкин, С. Харламов // Армейский сборник. 2003. - № 2 (104). - C. 5-9.

2. Бек, У. Что такое глобализация? / У. Бек. М. : Прогресс-Традиция, 2001. - 304 с.

3. Горин, Д. Г. Пространство и время в динамике российской цивилизации / Д. Г. Горин. - М. : Едиториал УРСС, 2003. - 280 c.

4. Гусейнов, А. А. Возможно ли моральное обоснование насилия? / А. А. Гусейнов // Вопросы философии. - 2004. - № 3. - С. 19-28.

5. Закон РФ от 6 марта 2006 г. № 35-Ф3 «О противодействии терроризму» : (с изм. от 6 июля 2016 г.) : (с изм. и доп., вступ. в силу с 1 янв. 2017 г.) // Собрание законодательства РФ. - 2006. - 13 марта. - № 11. - Ст. 1146.

6. Иванова, Е. М. Уровни осуществления полилога с позиции теории коммуникативного действия Ю. Хабермаса и их влияние на трансформацию традиционных концепций диалога в полилог / Е. М. Иванова, В. А. Пономарев // Вестник Челябинского государственного университета. Серия «Философия. Социология. Культурология». 2013. - № 33 (324). - С. 118-123.

7. Кастельс, М. Становление общества сетевых структур / М. Кастельс // Новая постиндустриальная волна на Западе. Антология / под ред. В. Л. Иноземцева). - М. : Academia, 1999. - С. 494-505.

8. Кафтан, В. В. Введение в террологию: логико-эпистемологические основания институционализации / В. В. Кафтан. - М. : ВУ, 2009. - 256 с.

9. Кожушко, Е. П. Современный терроризм. Анализ основных направлений / Е. П. Кожушко. Мн. : Харвест, 2000. - 448 c.

10. Лакер, У. Новый терроризм / У. Лакер // Международные терроризм и право. - М. : ИНИОН PAH, 2002. - C. 7-25.

11. Малышева, Е. Н. Феномен современного терроризма: социально-философский анализ : автореф. дис. ... канд. филос. наук / Малышева Елена Николаевна. - Красноярск, 2011. - 23 с.

12. Мертон, Р. Социальная структура и аномия / Р. Мертон // Социология преступности (Современные буржуазные теории). - М. : Прогресс, 1966. C. 299-313.

13. Назаркин, М. В. Формирование системы предупреждения технологического терроризма: правовые и организационные аспекты / М. В. Назаркин. - М. : ВНИИ МВД России, 2004. - 118 с. 
14. Октябрьский, П. Я. Россия сегодня: проблемы демографии / П. Я. Октябрьский // Вопросы статистики. - 2007. - № 4. - С. 44-47.

15. Петрищев, В. Е. Заметки о терроризме / В. Е. Петрищев. - М. : Эдиториал УРСС, 2001.$288 \mathrm{c}$.

16. Сейджман, М. Сетевые структуры терроризма / М. Сейджман. - М. : Идея-Пресс, 2008. $216 \mathrm{c}$

17. Супертерроризм: новый вызов нового века / А. Бедрицкий, А. Змеевский, В. Лепский [и др.] . М. : Права человека, 2002. - 392 с.

18. Толстой, Л.Н.Путь жизни / Л. Н. Толстой. М. : Республика, 1993. - 431 с.

19. Удовик, С. Л. Глобализация: семиотические подходы / С. Л. Удовик. - М. : Рефлек-бук ; Киев : Ваклер, 2002. - 480 с.

20. Устинов, В. В. Обвиняется терроризм / В. В. Устинов. - М. : ОЛМА-ПРЕСС, 2002. - 416 с.

21. Фазылова, Т. Ф. Социально-философский анализ теории и практики терроризма : автореф. дис. ... канд. филос. наук / Фазылова Татьяна Федоровна. - Красноярск, 2011. - 24 с.

22. Федотова, В. Г. Хорошее общество / В. Г. Федотова. - М. : Прогресс-Традиция, 2005. $544 \mathrm{c}$.

23. Яшлавский, А. Джихадисты из Европы на Ближнем Востоке: скрытая и явная угроза / А. Яшлавский // Мировая экономика и международные отношения. - 2015. - № 10. - С. 18-29.

24. Castells, M. The rise of the network society, with a new preface. Vol. I : The information age: economy, society, and culture / M. Castells. Singapore: Wiley-Blackwell, 2010. -656 p.

25. Mallison, W. T. The concept of public purpose terror in international law / W. T. Mallison, S. V. Mallison // Journal of Palestine Studies. - 1975. Vol. IV, no. 2. - P. 36-41.

26. Wilkinson, P. Political terrorism/ P. Wilkinson.L. : Macmillan, 1974. $-267 \mathrm{p}$.

27. Wilkinson, P. Terrorism and the liberal state / P. Wilkinson. - Basingstoke; L. : MacMillan Press, 1986. $-322 \mathrm{p}$

\section{REFERENCES}

1. Batyushkin S., Kharlamov S. Vaktsina ot «chumy»[Vaccine against Plague]. Armeyskiy sbornik, 2003, no. 2 (104), pp. 5-9.

2. Bek U. Chto takoe globalizatsiya? [What is Globalization?]. Moscow, Progress-Traditsiya Publ., 2001.304 p.

3. Gorin D.G. Prostranstvo i vremya v dinamike rossiyskoy tsivilizatsii [Space and Time in the Dynamics of Russian Civilization]. Moscow, Editorial URSS Publ., 2003. 280 p.
4. Guseynov A.A. Vozmozhno li moralnoe obosnovanie nasiliya? [Is It Possible to Justify Violence Morally?]. Voprosy filosofii, 2004, no. 3, pp. 19-28.

5. Zakon RF ot 6 marta 2006 g. № 35-FZ «O protivodeystvii terrorizmu» (s izm. ot 6 iyulya $2016 \mathrm{~g}$.) (s izm. i dop., vstup. v silu s 1 yanv. 2017 g.) [Law of the Russian Federation of March 6, 2006 no. 35-FL "On Terrorism Prevention" (with amend. of July 6, 2016) (with amend. and add. come in force from January 1, 2017)]. Sobranie zakonodatelstva RF [Collected Legislation of the Russian Federation], 2006, March 13, no. 11, art. 1146.

6. Ivanova E.M., Ponomarev V.A. Urovni osushchestvleniya poliloga s pozitsii teorii kommunikativnogo deystviya Yu. Khabermasa i ikh vliyanie na transformatsiyu traditsionnykh kontseptsiy dialoga v polilog [Levels of Implementing the Dialogue from the Viewpoint of Ju. Habermas's Communicative Action Theory and Their Influence on Transformation of Conventional Concepts of Dialogue into Polylogue Transformation]. Vestnik Chelyabinskogo gosudarstvennogo universiteta. Seriya "Filosofiya. Sotsiologiya. Kulturologiya”, 2013, no. 33 (324), pp. 118-123.

7. Castells M. Stanovlenie obshchestva setevykh struktur [Formation of the Network Society]. Inozemtsev V.L., ed. Novaya postindustrialnaya volna na Zapade. Antologiya [New Post-Industrialization Wave in the West. Anthology]. Moscow, Akademiya Publ., 1999, pp. 494-505.

8. Kaftan V.V. Vvedenie v terrologiyu: logikoepistemologicheskie osnovaniya institutsionalizatsii [Introduction into Terror Studies: Logical and Epistemological Fundamentals of Institutionalization]. Moscow, VU Publ., 2009. 256 p.

9. Kozhushko E.P. Sovremennyy terrorizm. Analiz osnovnykh napravleniy [Present-Day Terrorism. Analysis of Basic Sub-Types]. Minsk, Kharvest Publ., 2000. 448 p.

10. Laker U. Novyy terrorizm [New Terrorism]. Mezhdunarodnye terrorizm i pravo [International Terrorism and Law]. Moscow, INION RAN Publ., 2002, pp. 7-25.

11. Malysheva E.N. Fenomen sovremennogo terrorizma: sotsialno-filosofskiy analiz: avtoref. dis. ... kand. filos. nauk [Phenomenon of Modern Terrorism: Social and Philosophical Analysis. Cand. philos. sci. abs. diss.]. Krasnoyarsk, 2011.23 p.

12. Merton R. Sotsialnaya struktura i anomiya [Social Structure and Anomia]. Sotsiologiya prestupnosti (Sovremennye burzhuaznye teorii) [Sociology of Crime (Modern Bourgeois Theories)]. Moscow, Progress Publ., 1966, pp. 299-313.

13. Nazarkin M.V. Formirovanie sistemy preduprezhdeniya tekhnologicheskogo terrorizma: 
pravovye i organizatsionnye aspekty [Formation of the System of Technological Terrorism Prevention: Judicial and Organizational Aspects]. Moscow, VNII MVD Rossii, 2004. 118 p.

14. Oktyabrskiy P.Ya. Rossiya segodnya: problemy demografii [Russia Today: Problems of Demography]. Voprosy statistiki, 2007, no. 4, pp. 44-47.

15. Petrishchev V.E. Zametki o terrorizme [Notes about Terrorism]. Moscow, Editorial URSS, 2001.288 p.

16. Seydzhman M. Setevye struktury terrorizma [Net Structures of Terrorism]. Moscow, Ideya-Press, 2008. $216 \mathrm{p}$.

17. Bedritskiy A., Zmeevskiy A., Lepskiy V., et al. Superterrorizm: novyy vyzov novogo veka [Super Terrorism: a New Challenge of the New Century]. Moscow, Prava cheloveka Publ., 2002. 392 p.

18. Tolstoy L.N. Put zhizni [Way of Life]. Moscow, Respublika Publ., 1993. 431 p.

19. Udovik S.L. Globalizatsiya: semioticheskie podkhody [Globalization: Semiotic Approaches]. Moscow, Reflek-buk Publ.; Kiev, Vakler Publ., 2002. 480 p.

20. Ustinov V.V. Obvinyaetsya terrorizm [Terrorism is Accused]. Moscow, OLMA-PRESS Publ., 2002. 416 p.
21. Fazylova T.F. Sotsialno-filosofskiy analiz teorii i praktiki terrorizma: avtoref. dis. ... kand. filos. nauk [Social and Philosophical Analysis of Theory and Practice of Terrorism. Cand. philos. sci. abs. diss.]. Krasnoyarsk, 2011.24 p.

22. Fedotova V.G. Khoroshee obshchestvo [A Good Society]. Moscow, Progress-Traditsiya Publ., 2005. 544 p.

23. Yashlavskiy A. Dzhikhadisty iz Evropy na Blizhnem Vostoke: skrytaya i yavnaya ugroza [Jihadists from Europe in the Middle East: Hidden and Open Threat]. Mirovaya ekonomika i mezhdunarodnye otnosheniya, 2015, no. 10, pp. 18-29.

24. Castells M. The Rise of the Network Society, With a New Preface. Vol. I: The Information Age: Economy, Society, and Culture. Singapore, WileyBlackwell, 2010.656 p.

25. Mallison W.T., Mallison S.V. The Concept of Public Purpose Terror in International Law. Journal of Palestine Studies, 1975, vol. IV, no. 2, pp. 36-41.

26. Wilkinson P. Political Terrorism. London, Macmillan, 1974. 267 p.

27. Wilkinson P. Terrorism and the Liberal State. Basingstoke; London, MacMillan Press, 1986. 322 p.

\section{Information About the Author}

Vladimir A. Ponomarev, Associate Professor, Department of Humanities and Foreign Languages, Yurga Institute of Technology (affiliated) National Research Tomsk Polytechnic University, Leningradskaya St., 26, 652055 Yurga, Russian Federation, PWA13@mail.ru.

\section{Информация об авторе}

Владимир Алексеевич Пономарев, доцент кафедры гуманитарного образования и иностранных языков, Юргинский технологический институт (филиал) Национального исследовательского Томского политехнического университета, ул. Ленинградская, 26, 652055 г. Юрга, Российская Федерация, PWA13@mail.ru. 